with the selection of the suitable colony of rats for four rat ascites tumors, including the Yoshida sarcoma ${ }^{3)}$, ascites hepatoma $7974^{4}$ ), ascites hepatoma $130^{5)}$ and nitromin resistant ascites hepaIoma 130 K. The colonies so far tested are indicated in Table 1, and the percent of lethal take (transplantation rate) and survival days of the intraperitoneal transplantation are observed. The cytological checking of the growth of tumor cell's and gross pathological findings of the dead animals are also carefuly undertaken with every rat as well. The results are shown in Table 3, 4, 5, 6, 7 as well as in Figures 1, 2, and several already reported results are summarized in Table 8 and 9. From these observations the followings might be pointed out as a summary.

1. The colony " $\mathrm{H}-1$ " (tentavively named, propagated originally from one pair of non-inbred rats by Dr. R. SATo and supplied in large scaels by Dr. J. KANEKo, Div. of Bacteriology of Hikari Factory, Takeda Pharmaceutical Ind., Ltd.) is the best in connection with the transplantation rate of the Yoshida sarcoma among several colonies so far tested. The colony "TH", which originated from one pair of the common colony with " $\mathrm{H}-1$ " and has been propagated by Mr. K. OsAwA, Tokyo, showed high susceptibility like the " $\mathrm{H}-1$ " colony, which will be supported by Dr. H. SATOH through his experiments with this colony.

2. There existed some colony ("C"-colony), the susceptibility of which to the transplantation of the Yoshida sarcoma is very poor, and it is suggested not to use such rats even for the keeping of the Yoshida sarcoma. It is also noted that some of non-inbred colony such as " $T$ " and/or "SD" is fairly good concerning the transplantation rate and is feasible to be used in practice, provided some adequate precaution ${ }^{16)}$ are given.

3. The life span of the Yoshida sarcoma for the year 1955, 1956 and 1957 was $7.28 \pm 0.12,7.53 \pm 0.16$ and $8.12 \pm 0.15$ days respectively and the range of deviation was found to be fairly narrow.

4. The transplantation rate and survival time of three ascites hepatomas were also compared among several colonies, and the " $\mathrm{H}-1$ " colony is considered to be suitable for the practical use for these tumors. It is also noted that there was no difference in the transplantation rate and survival days among the ascites hepatoma 130 and nitromin resistant ascites hepatoma130K which was induced from the former. (with technical assistance of T. KomETA)

\title{
“Donryu-rat” 吉田肉腫高感受性の「1コロニー」Кつ々て
}

\section{日本実験動物研究会癌専門部会 吉 田 富 三}

癌研究において 移植性腫沮が有力な研究手段である が，宿主として使用する動物にも適切なコロニー（族） を選ぶことが必要であることは論を俟たない。わが国で 広く使用されている吉田肉腫については数年来雑婚動物 ではあるが，感受性の高い「コロニー」が注目されてい て，それについての名称を使用の便宜の為に定めよ5と ゆう示唆が, 安東洪次理事長から提言されたので, 癌専 問部会の部会員および関係者の 御協力を得て資料を集 め, 名称について次のような案を得たので, 茲に報告し 御参考に資したい。

I 名称 Donryu-rat 又は Donryu 族ラット 「系」とゆう言葉は当分さけた方がよいと思われる。 このラットについて，これまで使用されていた名称は
「吞龍」「S 系」「H-1 (系)」などであり, また提案され たものはこの他には「Donryu-S 系」「Donryu 系」「YS」 「sys」などがあつたが, Donryu は最も支持者が多かつ た。このラットは 1950 年群馬県太田市で佐藤隆一が太 田市動物商から購入した雑婚雌雄 2 匹から繁殖し, 1952 年より約 1 年間佐々木研究所および薬理研究所で, 佐藤 隆一の得た高感受性が追試されて以来注目されたコロニ ーである。

\section{Donryu-rat の吉田肉腫移植成栍}

(1) [佐藤隆一の報告1)]

1950１957 まで計 927 頭についての成績は第 1 表に 示すように陰性は 1 例のみで腹壁皮下に $2 \times 2 \mathrm{~cm}$ の腫 瘤をつくりこれが慣死を接こして治病した。 
Table 1. Survival Days of 927 Donryu-rats Intraperitoneally Transplanted with the Yoshida Sarcoma (1950-1957)

(Ryuichi Sato, Oizumi-cho, Gumma Pref.)

\begin{tabular}{|cc|}
\hline $\begin{array}{r}\text { Survival } \\
\text { days }\end{array}$ & $\begin{array}{r}\text { Nos. rats } \\
\text { died }\end{array}$ \\
\hline 5 & 12 \\
6 & 156 \\
7 & $\mathbf{3 2 0}$ \\
8 & 248 \\
9 & 104 \\
10 & 33 \\
11 & 21 \\
12 & 12 \\
13 & 5 \\
14 & 4 \\
15 & 2 \\
16 & 7 \\
17 & $\cdot$ \\
18 & $\cdot$ \\
19 & $\cdot$ \\
20 & $\cdot$ \\
21 & 1 \\
22 & 1 \\
\hline Negative & 1 \\
\hline
\end{tabular}

(2)【薬理研究所佐藤 博の成䋶2)]

1953 から 1957 まで 合計 1062 頭について の成績は第 2 表打よび 第 1 図に示すよ5に有 効動物 1036 頭全例移 植陽性でその生存日数 のモードは 7 日であつ た。

通常の 累代移植の ときの移植細胞数は 1,000万〜100万である が, この点について吟 味を加え, 細胞数を減 少してゆき最低 100 ま での場合の成績は第 3 表および第 2 図に示す この成績から 10,000 個 の細胞でも移植率 100\%であり，また細胞数を減少する につれ，生存日数が長くなることがあきらかになつた。

更に又，佐藤（博）は之等の動物を用いて実験した場 合の具体的な例を報告している。即ち, 癌の化学療法実 験に於て薬凧の効果を延命により判定しようとする場

Table 2. Percent Survival of 1062 Donryu-rats Intraperitoneally Transplanted with the Yoshida Sarcoma (1953-1957)

(Hiroshi Satoh, Iatrochemical Inst., Tokyo)

\begin{tabular}{|c|c|c|c|c|c|c|c|}
\hline \multicolumn{2}{|c|}{ Year } & 1953 & 1954 & 1955 & 1956 & 1957 & Total \\
\hline \multicolumn{2}{|c|}{$\begin{array}{l}\text { Nos. animal } \\
\text { Invalid } \\
\text { Valid }\end{array}$} & $\begin{array}{r}19 \\
1 \\
18\end{array}$ & $\begin{array}{r}302 \\
5 \\
297\end{array}$ & $\begin{array}{r}305 \\
12 \\
293\end{array}$ & $\begin{array}{r}220 \\
4 \\
216\end{array}$ & $\begin{array}{r}216 \\
4 \\
212\end{array}$ & $\begin{array}{r}1062 \\
26 \\
1036\end{array}$ \\
\hline 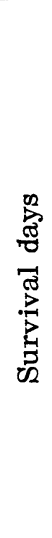 & $\begin{array}{r}4 \\
5 \\
6 \\
7 \\
8 \\
9 \\
10 \\
11 \\
12 \\
13 \\
14 \\
15 \\
16 \\
17 \\
18 \\
19 \\
20 \\
34 \\
36\end{array}$ & $\begin{array}{l}7 *(61.1) * * \\
8(16.6) \\
2(5.6) \\
1(0)\end{array}$ & $\begin{array}{r}13(95.6) \\
41(81.8) \\
79(55.2) \\
73(30.6) \\
55(12.1) \\
26(3.4) \\
5(1.7) \\
5(0)\end{array}$ & $\begin{array}{r}1(99.7) \\
9(96.6) \\
58(76.8) \\
92(45.4) \\
70(21.6) \\
35(9.6) \\
20(2.7) \\
7(0.3) \\
1(0)\end{array}$ & $\begin{array}{r}3(98.6) \\
18(90.3) \\
\mathbf{5 6}(64.4) \\
53(39.8) \\
47(18.1) \\
26(6.0) \\
9(1.9) \\
2(0.9) \\
\dot{1}(0.5) \\
:\end{array}$ & $\begin{array}{r}17(92.0) \\
\mathbf{6 3}(62.3) \\
57(35.4) \\
35(18.9) \\
19(9.9) \\
7(6.6) \\
4(4.7) \\
1(4.2) \\
3(2.8) \\
. \\
1(2.4) \\
2(1.4) \\
1(0.9) \\
. \\
\dot{1}(0.5) \\
1(0)\end{array}$ & $\begin{array}{r}1(99.9) \\
25(97.5) \\
134(84.6) \\
297(55.9) \\
261(30.7) \\
174(13.9) \\
92(5.0) \\
28(2.3) \\
12(1.2) \\
1(1.1) \\
4(0.7) \\
\cdot 1(0.6) \\
2(0.4) \\
1(3.3) \\
\cdot \\
1(0.2) \\
1(0.1) \\
1(0)\end{array}$ \\
\hline Tra & $\begin{array}{l}\text { n- } \\
\text { rate }\end{array}$ & 100 & 100 & 100 & 100 & 100 & 100 \\
\hline
\end{tabular}

* : Nos. rat died

** : Percent survival

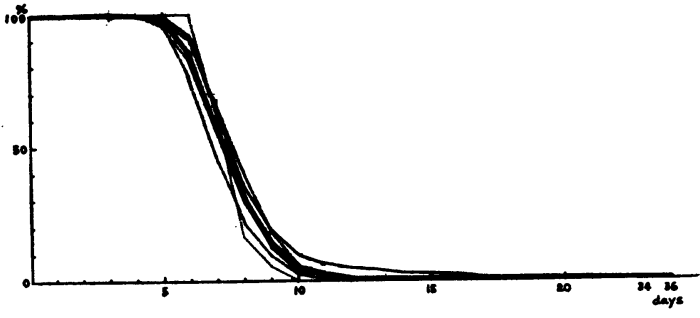

Fig. 1 (Table 2) Percent Survival of the Yoshida Sarcoma in Donryu-rats (Table 2)

合, 吉田肉腫 Donsyu-rat は極めて敏感にその成績を 示すことが判つた。特に移植細胞数を減少させた場合で は，従来の日本産雑婚白鼠では見られない良好な成績が 得られ，効果判定が極めて簡単であり良好な実験動物で あることを示している。

(3) [佐〉木研究所井坂英彦の成績]

1952 年 4 月から 1954 年 1 月までの 122 頭の成續およ び 1956 年 164 頭の成績（移植細胞数 1,000 万）はそれ ぞれ移植率 $100 \%$ および $99.4 \%$ 平均生存日数 8.1 およ び 6.5 日であつた。

\section{(4)【福島大学病理佐藤春郎の成績]}

1956 年約 150 頭（累代移植 65 代）のなかで自然治 癒例 1 頭もなく，結節を生じ腹水中の増殖のよくなかつ たもの 2 頭。平均生存日数 8 日。

(5)〔武田研究所 梶原 㵽の成績 ${ }^{3}$ ]

1955 年から 1957 年まで 計 686 の動物についての成 績は第 5 表に示すように移 植率 100\% またはこれに近 く, 生存日数は 7 日余であ つた。

また第 6 図に示すように Donryu-rat は腹水肝癌 130 に対しては感受性がよ いが腹水肝癌 7974 に対し ては $90 \%$ 前後であること は注意される。

(6)〔Donryu-rat 以外に ついての報告】

北大理学部牧野佐二郎 ${ }^{4)}$ から Wistar/Ma, Wistar 多産, Wistar-King/Ma, Wistar Pacific, Gifu, Tokyo, Castlés Black $\times$ Wistar King A, LongEvans, Buffalo, Fisher 
Table 3. Changes in Survival Days of Donryu-rats with Various Number of Inoculum (Hiroshi Satoh, Jatrochemical Inst., Tokyo)

\begin{tabular}{|c|c|c|c|c|c|c|c|c|}
\hline \multicolumn{2}{|c|}{$\begin{array}{l}\text { Cell number } \\
\text { of inoculum }\end{array}$} & 100 & 1,000 & 5,000 & 10,000 & 100,000 & \multicolumn{2}{|c|}{$1,000,000^{10,000,}, 000$} \\
\hline 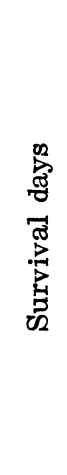 & $\begin{array}{r}5 \\
6 \\
7 \\
8 \\
9 \\
10 \\
11 \\
12 \\
13 \\
14 \\
15 \\
16 \\
17 \\
18 \\
19 \\
20 \\
21\end{array}$ & $\left|\begin{array}{cc}1 *(90) * * \\
\dot{2} \\
2(70) \\
2 & (50) \\
2 & (10)\end{array}\right|$ & $\begin{array}{cc}1 & (90) \\
1 & (80) \\
3 & (50) \\
3 & (50) \\
1 & (10) \\
\cdot & \\
\dot{1} & (0)\end{array}$ & $\begin{array}{ll}2 & (80) \\
1 & (70) \\
3 & (40) \\
2 & (20) \\
2 & (0)\end{array}$ & $\begin{array}{ll}1 & (90) \\
3 & (60) \\
3 & (30) \\
2 & (10) \\
1 & (0)\end{array}$ & $\begin{array}{l}6(40) \\
4(0)\end{array}$ & $\begin{array}{l}2(80) \\
4 \quad(40) \\
4 \quad(0)\end{array}$ & $\begin{array}{l}4(60) \\
4(20) \\
2(0)\end{array}$ \\
\hline Tra & & 90 & 100 & 100 & 100 & 100 & 100 & 100 \\
\hline
\end{tabular}

*, ** : Refer to Table 2.

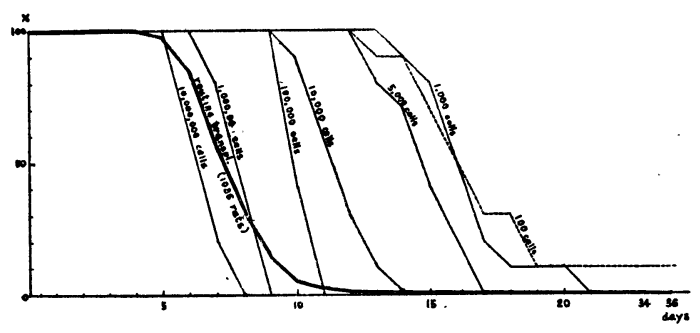

Fig. 2 Percent survial of Yoshida tumor in Donryu-rats (Table 3)

Table 4. Results of the Intraperitoneal Transplantation of the Yoshida Sarcoma in Donryu-rats

\begin{tabular}{|l|c|c|}
\hline \multicolumn{1}{|c|}{ Year } & $\begin{array}{l}\text { From Apr. 1952 } \\
\text { To }\end{array}$ & $1956 *$ \\
\hline $\begin{array}{l}\text { Nos. animals } \\
\text { Valid rats }\end{array}$ & 122 & 164 \\
Take & 115 & 164 \\
\hline $\begin{array}{l}\text { Transplantation } \\
\text { rate }\end{array}$ & 100.0 & 163 \\
\hline Survival days & $8.1(5-18)$ & $6.5(5-8)$ \\
\hline \multicolumn{2}{|c|}{ * Inoculum : 10 million/rat } \\
\hline
\end{tabular}

(Hidehiko Isaka, Sasaki Inst., Tokyo)

\begin{tabular}{|l|l|l|l|l|}
\hline \multicolumn{1}{|c|}{ Year } & 1955 & 1956 & 1957 & Total \\
\hline $\begin{array}{l}\text { Nos. animals } \\
\text { Take }\end{array}$ & 194 & $\begin{array}{l}257 \\
253\end{array}$ & $\begin{array}{l}235 \\
233\end{array}$ & $\begin{array}{l}686 \\
680\end{array}$ \\
\hline $\begin{array}{l}\text { Transplanta- } \\
\text { tion rate (\%) }\end{array}$ & 100 & 98.3 & 99.15 & 99.1 \\
\hline $\begin{array}{l}\text { Survival days } \\
\text { S. E. }\end{array}$ & $\begin{array}{l}7.28 \\
\mathbf{0 . 1 2 3}\end{array}$ & $\begin{array}{l}7.53 \\
\mathbf{0 . 1 6 7}\end{array}$ & $\begin{array}{l}8.12 \\
\mathbf{0 . 1 4 7}\end{array}$ & \\
\hline
\end{tabular}

(Kyo Kaziwara, Takeda Inst., Osaka)
についての成績が第 5 表のよ5 に示された。

な㸱これに関連するものとし て佐藤春郎らのアメリカでの 12 の系統での成績（第 6 表）执よ び佐藤春郎 ${ }^{6}$, , 佐藤博 ${ }^{7}$, 梶原 㽬8)らの日本産雑婚ラットにつ いての吉田肉腫発見当時からの 移植率 (第 7 表) が参考とされ よ5。

\section{(7) 成績の総括}

以上の諸成績をまとめてみる と第 9 表のごとくになる。すな わち Donryu-rat については 独立した 5 カ所の研究室で合計 約 3000 余の動物について観察 した結果, いずれも吉田肉腫に 対する 移植率極めて高く 99100\% を示し, また生存日数も 7〜8 日で一致した成績 を示した。在来の日本産雑婚白鼠についての成績よりも 良好なことはあきらかであるといえよう。

しかしながらこの Donryu-rat にも時に陰性例や生 存日数の長いいわゆる異常経過例が少数存在し, またす ベての実験がこのコロニー内の雑婚繁殖によつて得た動 物を使用したものであることを考え, 命名は使用上の便 宜で行つたにすぎないことを附記したい。

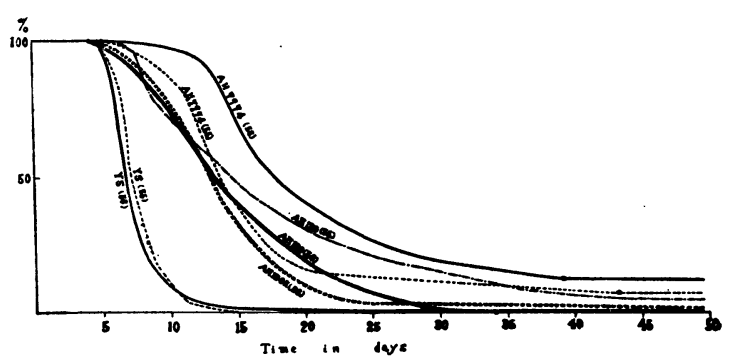

Fig. 3. Percent Survival of 4 Rat Ascites Tumors in Donryu-rats (Table 4)

\section{Donryu rat $の$ 繁殖の現況}

第 10 表に示すよ $5 に$ 佐藤隆一, 大沢飼育場, 武田楽 工光工場で繁殖し, 現在月産約 800, 兄妹交配では F-11 までになつている。また大沢飼育場では他のラット（ウ ィスターおよび大沢雑婚) に比して性格稍粗暴と称して いる。量座の能率に関連する基本的数值の 1 部が大沢飼 育場から第 11 表のごとく提出されたが，他のラットに 比較して Donryu-rat は平均仔数, 平均離乳仔数少く ㅇ 親の妊娠率低く哺乳率も悪く, また出産仔に ᄋ少く, 量産は容易ではないとゆう結論を出しているが, 他の 2 カ所の繁殖実施上は量産容易と報告している。 
Table 5. Transplantation Rate and Survival Days of the Yoshida Sarcoma in Various Strains of Rats

(S. Makino; Dpt. Science, Hokkaido Univ.)

\begin{tabular}{|c|c|c|c|c|c|c|c|c|}
\hline \multirow{2}{*}{$\begin{array}{c}\text { Strains of } \\
\text { rats** }\end{array}$} & \multicolumn{2}{|c|}{ Subline A* } & \multicolumn{2}{|c|}{ Subline B* } & \multicolumn{2}{|c|}{ Subline C* } & \multicolumn{2}{|l|}{ Subline D* } \\
\hline & Take $(\%)$ & Sur. d. & Take $(\%)$ & ur. d. & Take $(\%)$ & Ir. d. & Take $(\%) \mathrm{St}$ & ir. d. \\
\hline A Wistar/Ma & 43/44 (98. ) & 9.3 & $29 / 31(93)$ & 8 & $72 / 74(97)$ & 9.0 & $60 / 61(98)$ & 10.2 \\
\hline B Wistar & - & - & - & - & $7 / 8 \quad(88)$ & 11.4 & $7 / 7 \quad(100)$ & 10.1 \\
\hline C Wistar-King/Ma & $8 / 8(100)$. & 8.5 & $10 / 10(100)$ & 9.2 & $11 / 13(85)$ & 15 & $13 / 14(93)$ & 14.9 \\
\hline D Wistar-Pacific & - & - & $4 / 4 \quad(100)$ & 13 & $4 / 5 \quad(80)$ & 8.0 & $4 / 4 \quad(100)$ & 15 \\
\hline E Gifu & $34 / 37(91.9)$ & 7.9 & $23 / 25(92)$ & 8.7 & $27 / 27(100)$ & 8.5 & $23 / 23(100)$ & 10.6 \\
\hline F Tokyo & $75 / 83(90.4)$ & 10.0 & $18 / 18(100)$ & 9.1 & $41 / 43(95)$ & 8.7 & $10 / 10(100)$ & 9.8 \\
\hline $\begin{array}{r}\text { G Castle's Blac'x } \\
\text { x King A }\end{array}$ & 19/27 (70. ) & 9.4 & $38 / 40(95)$ & 8.8 & $40 / 45(89)$ & 10.2 & $26 / 29(89)$ & 14.9 \\
\hline H Long-Evans & - & - & $7 / 10(70)$ & 12 & $4 / 4 \quad(100)$ & 9.5 & $3 / 4 \quad(75)$ & 7.7 \\
\hline I Buffalo & - & - & $2 / 2 \quad(100)$ & 11.0 & $2 / 6 \quad(33)$ & 16.5 & $3 / 4 \quad(75)$ & 10.7 \\
\hline G Fisher & 一 & - & ( 57) & 13.3 & $0 / 25(0)$ & - & $15 / 18(83)$ & 13.0 \\
\hline
\end{tabular}

* Subline A, B, C and D of the Yoshida sarcoma will be published elsewhere.

** Origin of each strain is as follows :

A : Wistar Institute (abbr. W. I.) $\rightarrow$ Dpt. Agriculture, Tokyo Univ. $\rightarrow$ Makino (1944)

B : established from W/Ma as a "tasan" strain (1952)

C: W. I. $\rightarrow$ Makino (1953)

D : Pacific Farms $\rightarrow$ City of Hope (1955) $\rightarrow$ Makino (1956)

$\mathrm{E}$ : From one dealer of "Gifu" district of Japan (1953)

F : From one dealer of "Tokyo" district of Japan (1952)

G : Castle's black mutant from Dr. Castle (1953)

H : Pacific Farms $\rightarrow$ Makino (1956)

I : Dr. Jay (N. I. H., Bethesda) $\rightarrow$ Makino (1956)

$\mathrm{J}:$ Ditto

Table 6. Results of Intraperitoneal Transplantation of theYoshida Sarcoma and Ascites Hepatoma in Various American Strains of Rats.

(Haruo Sato, $\S$ National Cancer Inst., Bethesda)

\begin{tabular}{|c|c|c|c|c|c|c|}
\hline \multirow{2}{*}{ Strain of rats } & \multicolumn{2}{|c|}{ Yoshida sarcoma } & \multicolumn{2}{|c|}{ AH 7974} & \multicolumn{2}{|c|}{$\mathrm{AH} 130$} \\
\hline & Nos. of rats & $\%$ Ta'se & Nos. of rats & $\%$ Take & Nos. of rats & $\%$ Take \\
\hline Japanese* & 125 & 94 & 86 & 94 & 76 & 93 \\
\hline M 5201) & 295 & 86 & 155 & 75 & 142 & 70 \\
\hline $\left.\mathrm{M} 520 \times \mathrm{AC}^{2}\right)$ & 213 & 82 & 127 & 77 & 102 & 68 \\
\hline Sprague-Dawley* & 104 & 52 & 45 & 27 & 43 & 26 \\
\hline Holtzman* & 87 & 51 & 38 & 24 & 17 & 24 \\
\hline Buffalo & 51 & 16 & 25 & 0 & 45 & 0 \\
\hline Wistar & 48 & 8 & 37 & 0 & 30 & 0 \\
\hline Osborne-Mendel & 73 & 8 & 99 & 12 & 68 & 13 \\
\hline NIH black* & 25 & 8 & & & & \\
\hline Fisher & 35 & 0 & 30 & 0 & 28 & 0 \\
\hline O'Grady & 45 & 0 & 35 & 0 & 35 & 0 \\
\hline Albany & 38 & 0 & 35 & 0 & 48 & 0 \\
\hline $\begin{array}{l}\text { * noninb } \\
\text { 1) abbre. } \\
\text { 2) F1 hyb }\end{array}$ & $\begin{array}{l}\text { strain } \\
\text { Marshall } 520 \\
\text { [Marshall } 520\end{array}$ & $(\mathbf{A} \times \mathbf{C}$ & 35) J $F 1$ & & & \\
\hline
\end{tabular}

$\S$ Present address: Fukushima Univ., Fukushima. 
Table 7. Results of Serial Transplantation of the Yoshida Sarcoma in Japanese Random Colony of Rats

(Hiroshi Satoh, Iatrochemical Inst., Tokyo)

\begin{tabular}{|r|r|r|r|r|r|r|}
\hline Year & Generation & $\begin{array}{c}\text { Nos. valid } \\
\text { rats }\end{array}$ & Take (\%) & Course of tumor growth \\
\hline 1943 & $1-19$ & 123 & $106(86.2)$ & 79.7 & 6.5 & 13.8 \\
1944 & $20-58$ & 376 & $362(96.4)$ & 94.0 & 2.4 & 3.6 \\
1945 & $59-88$ & 142 & $118(83.1)$ & 78.9 & 4.2 & 16.9 \\
1946 & $89-120$ & 133 & $127(95.5)$ & 88.0 & 7.5 & 4.5 \\
1947 & $121-159$ & 86 & $81(94.2)$ & 89.5 & 4.7 & 5.8 \\
1948 & $160-197$ & 60 & $57(95.0)$ & 93.3 & 1.7 & 5.0 \\
1949 & $198-246$ & 116 & $109(93.9)$ & 93.1 & 0.8 & 6.1 \\
1950 & $247-299$ & 160 & $133(83.1)$ & 89.3 & 3.8 & 16.9 \\
1951 & $300-346$ & 245 & $235(95.8)$ & 91.0 & 4.8 & 4.2 \\
1952 & $347-397$ & 190 & $172(90.5)$ & 86.3 & 4.2 & 9.5 \\
1953 & $398-413$ & 93 & $88(94.5)$ & 93.5 & 1.0 & 5.5 \\
\hline Total & $1-413$ & 1724 & $1588(92.1)$ & 88.3 & 3.8 & 7.9 \\
\hline
\end{tabular}

* A : Take, normal course

B : Take, abnormal course with prolonged survival

C: Negative

Table 8. Summarized Data of the Transplantation Rate and Survival Days of Donryu-Rats Intraperitoneally Transplanted with the Yoshida Sarcoma

\begin{tabular}{lcrll}
\hline \multicolumn{1}{c}{ Name of rats } & Nos. valid rats & $\begin{array}{c}\text { Transplantation } \\
\text { rate }\end{array}$ & Survival days & Reference \\
\hline Donryu, R. Sato Farm & 927 & 99.9 & about 8 & R. Sato, Table 1 \\
Donryu, Osawa Farm & 1036 & 100.0 & mode 7 & H. Satoh, Table 2 \\
Donryu, R. Sato Fram & 122 & 100.0 & average 8.1 & H. Isaka, Table 4 \\
Donryu, Osawa Farm & 164 & 99.4 & average 6.5 & H. Isaka, Table 4 \\
Donryu, Osawa Farm & 150 & 100.0 & about 8 & H. Sato. \\
Donryu, Hikari Factory & 686 & 99.1 & about 8 & K. Kaziwara, Table 4 \\
\hline Japanese random colony & 1724 & 88.3 & average 11 & H. Satoh, Table 7 \\
\hline
\end{tabular}

Table 9. The Present Situation of the Breeding of Donryu-rats (Jan. 1958)

\begin{tabular}{|c|c|c|c|}
\hline Name of facility & R. Sato Farm & Osawa Farm & $\begin{array}{c}\text { Hikari Factory } \\
\text { Takeda Pharmaceut. Comp. }\end{array}$ \\
\hline Start of breeding & 1950 & 1950 & 1953 \\
\hline Breeding System & Random & Random & $\begin{array}{l}\text { Random and Brother- } \\
\text { Sister }(\mathbf{F}-11)\end{array}$ \\
\hline Nos. supply per month & 50 & 250 & 600 \\
\hline Supply to & None & $\begin{array}{l}\text { Iatrochemical Inst. } \\
\text { Sasaki Inst. } \\
\text { Fukushima Univ. } \\
\text { Gerontology Inst. }\end{array}$ & Takeda Inst. \\
\hline $\begin{array}{l}\text { Possibility of increase } \\
\text { in supply }\end{array}$ & Yes & Yes, up to $500 /$ month & Yes, uy to $1300 /$ month \\
\hline Easiness of breeding & Yes & No (Refer to Table 10 ) & Yes \\
\hline
\end{tabular}


Table 10. Litter Size, Sex ate and Pregnancy Rate of Donryu-rats

(K. Osawa Farm, Fataba-cho, Shinagawa-ku, Tokyo)

\begin{tabular}{|c|c|c|c|}
\hline Name of colony & Donryu-rats & Wistar & Osawa non-inbred \\
\hline \multirow{2}{*}{$\begin{array}{l}\text { Average nos. litter born per weaning mother } \\
\text { Average nos. weaned litter per weaning mother }\end{array}$} & $8.4(167 \S)$ & $9.7(485)$ & $8.4(117)$ \\
\hline & $6.3(126)$ & $8.1(404)$ & $6.5(91)$ \\
\hline \multirow{3}{*}{$\begin{array}{l}\text { Percent of weaning mother per born mother } \\
\text { Percent of pregnant mother per mated female* } \\
\text { Percent of pregnant mcther per mated } \\
\text { old female** }\end{array}$} & $80.6(25 / 31)$ & $89.3(50 / 56)$ & $86.3(17 / 19)$ \\
\hline & 77 & 94 & 81 \\
\hline & 13 & 62 & 28 \\
\hline Sex rate of babies (female to male, $\%$ ) & $80.5(2,600)$ & $102.2(20,000)$ & $88.6(10,000)$ \\
\hline
\end{tabular}

* Under 1 year old

** 1 to $1 \frac{1}{2}$ years old

$\S$ Number of observation

N 総 括

1. 1950 年以来 1 対の雌雄から 雑婚交配で 繁殖を始 め 1952 年以来吉田肉腫に対する感受性が高いことが注 目されてきた。ラットのコロニーについて，5つの互に 独立した研究室で約 3000 頭に及ぶ動物の吉田肉腫腹腔 内移植成樍は 99-100\%, 生存期間は約 7 8 日で, 市販 日本産雑婚白鼠より膏い感受性を示すことが判明した。

2. このラットに対して使用上便宜の為に今後 Donryu-rat と呼びたい。すなわち吉田肉腫に対する感受 性の高いラットの 1 族を Donryu-rat とする。

3. Donryu-rat の繁殖の現況を調查した。

終りにこの調查に御協力された下記の諸氏および日本 実験動物研究会の安東洪次, 田嶋嘉雄両教授に感謝した い。

記 広野蹋(名大病理), 井坂英彦(佐々木研), 梶原 㽬(武田研)，金子順一(武田光工場)，牧野佐二郎 (北大動物), 大沢欣三郎(大沢飼育場), 佐藤隆一
(佐藤医院), 佐藤春郎 (福島病理), 佐藤 博 (薬 理研), 土川 清 (遗伝研), 蔽岡小太郎 (癌研), 山本 正(伝研),

(敬称略)
交献
1）佐藤隆一, (1954)：慶応医学., 31. 329
2) 佐藤 博, (1956)：癌., 47. 380.
3）暒原 彊, 米田友彦, (1957)：武田研究所年報.

16. 100 .

4) Makino, S. and Sasaki M : Cotological study of tumor XXI. (in press)

5) Sato, H. (1955) : J. Nat. Cancer Inst., 15. 1367.

6）佐藤春郎, (1950)：癌., 41. 238.

7) 佐藤 博, (1956)：日本病理学会誌., 44. 392.

8）榐原 疆，井坂英彦，阪井敏治 (1952)：癌, 43. 276.

Donryu-rat, a colony of Japanese noninbred rat which is highly suscepteble to the intraperitioneal transplantation

of the Yoshida ascites sarcoma.

Committee on experimental cancer resarch, Japan Experimental Animals Research Association Tomizo YOSHIDA

Suggested by Dr. K. Ando, Director of the Japan Experimental Animals Research Association, to decide the name of a colony of Japanese rats which have been proliferated from single pair by random breeding since 1950 and were noticed to be highly susceptible to the Yoshida sarcoma in 1952, the committee on experimental cancer research of the Association discussed the experimental results obtained among the scientists concerned* and have got the following conclusion.

1. It was confirmed from the results of 5 independent laboratories using more than 3,000 animals 
that the rats belonging to this colony are very susceptible to the intraperitoneal transplantation of the Yoshida sarcoma. The rate of the transplantation is $99-100 \%$, significantly higher than $88.3 \%$ in Japanese random colony from dealers, and 94 to $0 \%$ in 12 American strains. The survival days of the Yoshida sarcoma bearing animal are uniformely 7 to8 days.

2. It was suggested to call this colony as "Donryu-rats" for the conveniency of the usage; Donryu is associated with the place where the animals were originally bred.

3. Present situations of the supply and the breeding of "Donryu-rats" have been checked with three independent fascilites.**

* The following scientists cooperated with the investigation.

I. Hirono: Dpt Pathology, Nagoya Univ., Med. School, Nagoya

H. Isaka : Sasaki Institute, Surugadai, Kanda, Tokyo

K. Kaziwara: Takeda Institute, Jyuso, Osaka

J. Kaneko: Hikari Factory, Takeda Pharmaceutical Co., Hikari, Yamaguchi-Pref.

S. Makino: Dpt. Zoology, Hokkaido Univ., Sapporo

K. Osawa: Osawa Farm., Futaba-cho, Shinagawa-ku, Tokyo

R. Sato: Sato Farm., Oizumi-cho, Gumma-Pref.

H. Sato: Dpt. Pathology, Fukushima Univ., Med. Scool, Fukushima-shi

H. Satoh: Jatrochemical Institute, Nishigahara, Kita-ku, Tokyo

K. Tsuchikawa: Institute of Genetics, Mishima, Shizuoka-Pref.

K. Warabioka: Institute of Cancer, Nishisugamo, Toshima-ku, Tokyo

T. Yamamoto: Institute of Infectious Diseases, Shibashiroganedai-machi, Minato-ku, Tokyo

** Drs. J. Kaneko, R. Sato and Mr. K. Osawa are taking care of the breeding so far checked.

\section{* * 文 献 抄 録 * *}

\section{感受性}

JANice Stadler, JohN W. Gowen (Iowa State Col.) (1957): Radiological Effects on Resistance Mechanisms of Genetically Differentiated Strains of Mice Exposed to Salmonella Typhimurium. J. Inf. Dis;, 100 (3), 284-299.

$\mathrm{S}, \mathrm{Z}, \mathrm{K}, \mathrm{Q}$, 及び Ba 系の生後 $46 \pm 3$ 日マウスにX 線を頭, 中軀, 後軀, 及びこれらの組合せ部位に $320 \mathrm{r}$, 480r, 友び 640r 照射し，15 日後に S. typhimurium をi.p. 接種して, 系統による自然抵抗性の差及びX線 による抵抗性の低下の状態をしらべている。Ba は感染 にもX線のみにも抵抗が極めて少く, 殆ど実験成績が判 定できないが，Qはこれにつぎ，Sは両者に抵抗があつ て，よく実験の目的を達する。 $\mathrm{Z}$ と Kはその中間であ る。抵抗のX線による減弱は照射量に関運し, 又部位で は頭部照射の影響が大きいが，全身の方がずつと影響が 大きい。

(渋木 実)

\section{感受性}

JANice StadLeR, John W. Gowen (Iowa State Col.), (1957): Radiation Effects on Active Acquired Immunity to Salmonella Typhimurium in Mice. J. Inf. Dis. 100 (3), 300-301.

$\mathrm{S}, \mathrm{Z}, \mathrm{K}, \mathrm{Q}$, 及び Ba 采の生後 $46 \pm 3$ 日マウスにX
線を頭，中彄，後軀，及びこれらの組合せ部位に $320 \mathrm{r}$, $480 \mathrm{r}, 640 \mathrm{r}$ 照射し, 15 日後に S. typhimurium を少 量 i.p. 接種して, 系統による自然抵坑性及びその X線 による低下をみたのち，36日後に生残マウスに初感染量 の 100 倍 i. p. 接種して, 免疫獲得の状態をしらべた。 X線照射は非照射群に比して免度がやや低いが, 照射量 及び部位は最初の抵坑性減弱影響のときに比べて重大で はない。免疫獲得の状態は最初の感染耐過の状態にほぼ 併行していて, 系統が重要な因子であるといえる。これ はワクチン接種に拈ける系統差の成績に一致している。

(湇木 実)

\section{感受性}

David Gale, Geraldine devesty (New Mexico) (1957): Response of Mice to Inoculations. of Both Candida Albicans and Escherichia Coli, II. The Effect of the Strains of Mice, J. Inf. Dis. 101 (1) , 48-50.

TF 系 (Taconic Farms) 及び Namru 采マウスに C. albicans i.v. 及び E. coli i.p. 接種し, その死 亡をみると, C. albicans では平均死亡時間は Namru の方が $\mathrm{TF}$ よりはるかに短かく, 又 $48 \mathrm{hr}$ の菌の $\mathrm{LD}_{50}$ は TF の $50 \times 10^{5}$ に比し, Namru では $6.5 \times 10^{5}$ で ある。 